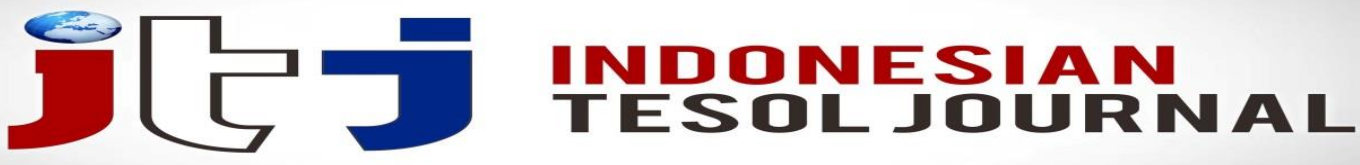

e-ISSN: 2622-5441(Online) Journal homepage: https://ejournal.iainpalopo.ac.id/index.php/ITJ/index

\title{
Japanese Students' Interaction Using Smartphone Apps: A Study of Young Learners in A Private High School
}

\author{
Jason Somerville \\ Kyorin University, Japan
}

Abstract: The widespread use of mobile devices plays a significant role in our everyday lives and has changed the way we communicate and interact. Mobile-Assisted Language Learning (MALL) offers numerous opportunities for learning inside the classroom with mobile devices no longer seen as only social and gaming devices. Research shows that mobile device applications (apps) are now valuable tools that are used for education and language learning, in particular for promoting learner collaboration and social interaction. The purpose of this study is to discover how smartphones and apps can support greater student interaction. With an increased number of educational institutions, namely private junior and senior high schools in Japan embracing mobile technology into classroom pedagogy, this study investigates which smartphone repurposed apps are useful for encouraging interaction between students. The significance of this research is beneficial for learners, teacher-educators and app developers in advancing the benefits of social interaction in second language acquisition (SLA) utilising mobile devices. Through qualitative structured observation of participants in a Tokyo high school classroom, this study explores which smartphone apps are the most successful in encouraging interaction measured by frequency counts. The quantitative data reveal which apps are the most suitable for supporting greater social interaction and collaboration between learners. The implications derived from the findings support the argument that smartphones provide increased student-student interaction and collaboration.

Keywords: Applications, Learner Collaboration, Smartphone, Student-Student Interaction

\section{INTRODUCTION}

Mobile phone apps are an essential ingredient in our everyday lives. With the rise in popularity of tablets and more specifically smartphones, these technologies have gradually changed the way we conduct ourselves. With the steady usage of smartphones frequently marketed as learning tools research shows that mobile device apps are now valuable for the purposes of education; there is a call to integrate technology into language learning (Kukulska-Hulme, 2009; Bicen and Kocakoyun, 2013; Chik, 2015). The mobility and flexibility of smartphones mean that they make optimal classroom learning companions and are significantly changing the ways of learning in SLA. Japan has been quick on the uptake of mobile 
phones with the number of smartphone users at 72.5 million in 2019 (statista.com, 2019). As ever-expanding numbers of people are learning English as a second or foreign language (Copland and Garton, 2014), the use of smartphones in MALL has great potential in the classroom to increase interaction and facilitate SLA.

This study is concerned with interaction between peers or student-student (Ss-Ss). The participants are all non-native speakers (NNS). Ss-Ss interaction is described as "any communicative activity carried out between learners, where there is minimal or no participation from the teacher" (Philp, Adams and Iwashita, 2014, p.3). How effective a learner interacts and communicates in the classroom with another learner gives support to the notion that interaction between peers plays an important role in the development of SLA (Frymier, 2005; Poulou, 2009; Parcha, 2014). Mobile technologies such as smartphones, provide support for social interactions and can enhance and expedite language learning (Ting, 2013). Using smartphones in a pedagogical environment as a mediated tool for SLA has provided positive results for interaction in the classroom (Brett, 2011; Chang and Vera Pa, 2011; Bicen and Kocakoyun, 2013).

Many high schools in Japan are now at a critical juncture and are about to embark on implementing mobile devices into classrooms. While debates about which technology to bring into the classroom are on-going, the pedagogy to help the learners learn must not be ignored. Simply having mobile devices in the classroom is not enough - teachers and learners need to know how to successfully use them. Several studies carried out research on mobile devices, apps, and interaction (Stuart, Brown and Draper, 2004; Kuo, 2011; Kim and Kwon, 2012; Chung, Lee, and Liu, 2013; Parcha, 2014; Chik, 2015; Cochrane, 2015; Pollard, 2015). However, none of these papers carried out empirical research in a Japanese high school context or demonstrate how 'repurposed' apps (which are not designed exclusively for language learning) can support better interaction between students. There is a gap in the research on how mobile apps in a typical Japanese Oral Communication (OC) classroom can be utilised to encourage better Ss-Ss interaction. Therefore, this study will attempt to bridge the gap and hopes to contribute valuable research to the field of MALL in bringing mobile devices, apps, and interaction together in one study. Accordingly, the following research question was formulated:

Which smartphone apps are the most successful at encouraging student-student interaction in second language learning?

\section{LITERATURE REVIEW}

Two theories that encompass interaction were acknowledged in this research study: The Interaction Hypothesis (Long, 1983, 1996) and Sociocultural Theory (Vygotsky, 1978). The Interaction Hypothesis (IH) is credited to Long in 1983 and updated in 1996. IH is interested in interaction known as negotiation of meaning, which occurs between learners through communication breakdown where learners ask for clarification and confirmation of comprehension (Long 1983). Sociocultural Theory (SCT) is an approach based on the work of Vygotsky (1978) and advocated by a host of researchers (Swain and Lapkin, 2001; Lantolf and 
Thorne, 2007) in which the major focus is that interpersonal interaction not only facilitates language learning but is a fundamental and causative force in SLA (Saville-Troike, 2006; Mitchell, Myles, and Marsden, 2013).

Stuart et al. (2004) provide an example of how the use of mobile technology handsets encourages a more dynamic form of student interaction. When questions were proposed to the learners in the classroom, students responded using handheld devices giving anonymous answers which motivated the learners (Zurita and Nussbaum, 2004); this is a form of learner-content interaction. The results of all responses on the main screen fostered learner-learner interaction with students keen to check their progress. This study enhanced student-student and student-teacher interaction via mobile devices through a non-threatening pedagogical environment (Ting, 2013).

A study in a Cypriot primary school carried out by Mavrou, Lewis, and Douglas. (2010), observed twenty pairs of students participating with shared computers that provided scaffolding on close-text and composition tasks. They discovered that the existence of technology aided the participation of the less proficient peers as well as providing a mediational role in peer interaction, which stimulated motivation and encouraged student discussion.

Gutiérrez (2006) investigated Spanish learners' progress, allowing collaborative language activities with computer assistance positioned on the claim by Swain (1997) that interaction conceivably promotes linguistic development via collective scaffolding (Donato, 1994). In her study with 18 college-level Spanish learners working on problem-solving tasks via software, she established a higher number of 'High Quality Collaboration' (HQC), which is defined as "learners, working within a ZPD, are able to co-construct language-related knowledge" (Gutiérrez, 2006, p.238). In addition, the learners were also found to engage further in negotiation of meaning and subsequent interactions in their L2.

Parcha (2014) reported on an activity that uses communication accommodation theory (CAT) and Twitter to help promote convergent communication among students (Giles, Mulac, Bradac and Johnson, 1987). CAT explores the adjustments such as speech, gestures, and vocal patterns which happen when people interact. Parcha (2014) opines that student-student connectedness plays a scaffolding role in encouraging meaningful interaction. The goal was to encourage students to engage in convergent communication inside and outside of the classroom. The example used in his paper was that before making a speech as an in-class assignment, students would prepare to post six tweets per week on Twitter use on the topics of Critique tweet, Speech topic tweet, Non-academic tweet, and Reply tweet. This four-week activity facilitated interaction outside of the classroom and students remarked how these interactions made the class feel more like a community. This, in turn, led to greater interaction inside the classroom with students able to discuss what they had shared with one another on Twitter.

Chung et al., (2013) conducted a study in Taiwan with nine university graduate students and set out to investigate how SDG influenced collaborative activities and how interaction played a role in promoting language learning. Multiple data sources were used such as mind maps, discourse, non-verbal interaction and questionnaire feedback, which yielded triangulation of analyses 
(Robson, 2012; Gray, 2014). The results were found to be highly in favour of SDG and mobile devices supporting face-to-face peer interaction. However, it was established that an SDG environment was more successful in generating discussion as opposed to group work with individual mobile devices. The results further demonstrated that SDG is valuable "in promoting information exchange, enhancing group communication, understanding learning tasks, and deepening group discussion" (Chung et al., 2013, p.203), which would be useful for teachers in generating greater peer interaction through collaboration in the classroom.

While research into student-student social interaction in the classroom is mostly positive, an investigation carried out by Kuo (2011) via qualitative semistructured interviews with participants in a British English as a Foreign Language (EFL) setting sought to find out student perceptions of interaction. The researcher questioned if interaction in SLA did actually facilitate SLA within a real classroom setting based on pedagogical inferences and linguistic exchanges between interlocutors, or whether student-student interaction was only helpful for assisting interpersonal and intercultural communication. It was found that 'unintelligibility' and 'linguistic inaccuracy' depicts a notable impediment on the positive effects of learner interaction on second language learning. Kuo (2011) cited the learners' need for corrective feedback and the lack of a more advanced other in scaffolding as a setback to the usefulness of classroom student-student interaction. She concluded that her investigation contradicted the "widely held assumption that one can best acquire a language by simply being in an environment where the language is spoken" (Kuo, 2011, p.289).

MALL has developed as a specialised field with an ever-expanding amount of literature dedicated to exploring and examining mobile devices used inside and outside the classroom (Fujimoto, 2012). Empirical research on using mobile devices for learning EFL has become a fashionable area of research - for example (Kim et al., 2013; Dashtestani, 2015). Kukulska-Hulme (2009) opines that the use of personal devices allows learners' ownership of learning and can lead to positive language learning experiences. Recent research for the purpose of education shows significant and positive results in L2 acquisition (Brett, 2011; Chang and Vera Pa, 2011; Bicen and Kocakoyun, 2013). Using mobile devices to collaborate has significant pedagogical implications for social interaction, as teachers and learners view mobile devices as mediated tools for online language learning (Caballe, Xhada and Baroli, 2010; Troussas, Virvou, and Alepis, 2014).

Cochrane (2015) explored beliefs and learning with smartphones with 146 Japanese university students, utilising a mixed methods approach of pre- and postintervention studies together with homework tasks, including a reflection component. A key rationale for Cochrane was that technology in Japanese education takes on a minor role with little time given to the use of technology for learning. Mobile devices are used principally for social or entertainment purposes, and when it comes to education, students preferred not to use them (Lockley and Promnitz-Hayashi, 2012; Takahashi, 2008). Tasks given in the lessons included reminders, time tracking, voice recorder, and Google apps, which were evaluated with different methods. The participants' reports were generally positive with students now organising their time, accessing dictionaries and recording speaking assignments. Many students reported improvements in their academic life; 
however, many learners felt anxious, which was accredited to the lack of teachercentred involvement.

Pollard's (2015) paper discusses activities using free messaging apps that are popular in Northeast Asia such as LINE (Japan) and Kakao Talk (Korea). These two apps are similar to the most popular messaging app - WhatsApp (www.whatsapp.com) which has found success worldwide. Pollard (2015) states that although the apps are free text-messaging services, they have the capability for group text, sharing of imagery, audio, and video they are already embraced by students and form part of communication in their everyday lives. The goal of Pollard's project was to increase the spoken ability of students by producing longer spontaneous segments of speech. He outlines three activities (1) Spoken Response, (2) Picture Prompt, and (3) Transcription, Consciousness-Raising and Noticing. The essential aim of Spoken Response is to develop fluency by recording a two to three-minute recording of a topic, which is sent to the teacher. Picture Prompt is an activity based on the Test of English for International Communication (TOEIC) (Educational Testing Service, 2019). The third activity moves onto listening with students transcribing their audio to experience consciousness-raising tasks and noticing which are features of self-monitoring (Schmidt 2001; Thornbury 2005; Ellis 2008). These activities demonstrate how the features of an app and a smartphone can motivate the language learner with the goal of increased spoken proficiency.

Chik (2015) conducted a study on 124 apps, examining the features of English learning apps for young learners. Interaction, connection, and collaboration are a part of the digital-mediated mindset. However, the results promoted an alternative view. Apps (using iOS from the Apple App Store) were searched using keywords: 'English', 'learning' and 'children'. The results showed that in the developers' descriptions of the apps, only 5 were purpose-built for EFL, and that most frequently used lexical items were: game (389 times) and fun (267 times), which is a strategy used to attract parents and younger learners, which emphasises fun over pedagogical practice (Nunan, 2013). Burston (2014) sees many of these apps as a less desirable characteristic of MALL. Apps are falsely advertised as autonomous learning when in fact learners are simply carrying out drilling exercise instruction (Holec, 1981) instead of taking control of their own learning (which is an interesting comparison of methodologies) and goes against the collaborative ethos of MALL: 'anytime, anywhere' (Kukulska-Hulme and Shield, 2008). Chik (2015) explained that parents (location unspecified) may be expecting a constructivist or sociocultural vision to learning; however, most of the apps embrace a behaviourist approach, which is regarded as one of the existing limitations of MALL (Burston, 2014). Chik (2015) concludes by urging meaningful interaction to take place in the EFL classroom and calls for a review of current pedagogical practice for MALL.

Kim and Kwon (2012) carried out a similar study evaluating 87 EFL apps, which corresponded with Chik (2015) in that the apps provided learner-centred chances with ubiquitous practice but collaborative learning styles would be more effective with an appeal for apps, which had an authentic context and encourage social interaction. Out of the 87 apps, only eight focused on speaking; most of the apps employed wordlists and grammatical items which were cognitively form- 
focused but again did not facilitate learning through interaction. Kim and Kwon (2012) opine that mobile apps are beneficial as a study reference but not as full instruction or as a replacement for classroom-based lessons.

\section{RESEARCH METHOD}

The current study took place within the confines of the OC department at a Japanese coeducational university-affiliated private high school in Setagaya ward in central Tokyo. The lessons were set up and designed to run like a typical OC lesson taught by a Native English Teacher (NET) with 36 participants. The students in this study are both a mixture of males and females and range from 14 to 17 years old with a CEFR level of between A1 and B1 with an IELTS score of up to 4.0 (see Table 1).

Table 1. Profile of Student Level

\begin{tabular}{rllll} 
Year & Age & CEFR & IELTS & TOEIC \\
\hline Junior 3 & $14-15$ & A1 & N/A & 300 \\
\hline Senior 1 & $15-16$ & A2 & N/A & 350 \\
Senior 2 & $16-17$ & B1 & 4.0 & 400
\end{tabular}

In this study, the researcher used a qualitative data collection method (structured observation) and analysed the data by quantitative means (frequency counts). This methodology relates to mixed methods research. The point of a mixed methods approach is for qualitative and quantitative research to complement each other and to end up with something that is larger than the sum of the parts, to some extent $1+1=3$ (Brown, 2014).

Structured observation or non-participant observation as it is also known was chosen as it was necessary to observe the participants in their 'natural setting' (i.e. classroom) without disturbance (Gray, 2014, Richards, 2003), and to acquire an unconnected 'pure observer' viewpoint (Robson and McCartan, 2016).

Data were measured by noting frequency counts of interaction (FCI), which meant that when an event occurred it was tallied on an observation schedule in the form of a checklist (Gray, 2014). A count of interaction in this study is defined as one instance of talk, vocalisation and physical communication. This was adapted from Beaver (2016) See Table 2 for what constitutes a count of interaction.

Table 2. Interaction Types and Counts

\begin{tabular}{|c|c|c|c|c|c|c|}
\hline Interaction & \multicolumn{6}{|c|}{ Count of interaction } \\
\hline Talk & question & response & suggestion & banter & & \\
\hline Vocalisation & affirming & yes & $\begin{array}{l}\text { active } \\
\text { listening }\end{array}$ & dissenting & no filler & skepticism \\
\hline $\begin{array}{l}\text { Physical } \\
\text { Communication }\end{array}$ & smile & laugh & scowl & $\begin{array}{l}\text { hand } \\
\text { movement }\end{array}$ & & \\
\hline
\end{tabular}

Video recording was employed in all of the lessons. Structured observation is concerned with capturing interaction as it occurs which relies on the subjectivity of the interpretations by the observer. By using video recording, this subjectivity can be greatly diminished (Croll, 1986; Caldwell and Atwal, 2005). 
Non-probability sampling for convenience (Gray, 2014) was adopted in identifying the participants for this study. This technique was used for convenience, as sampling involves gaining access to the most easily accessible participants, and in this case, it is for students who own a smartphone with a cellular data connection as there was no Wi-Fi available.

Structured observation was used for the collection of quantifiable data in this study to find out if smartphones support greater student interaction in L2 learning. After the data were collected, the researcher viewed all of the lessons repeatedly, noting FCI. Once the data was assembled, it was analysed for frequency distribution using Microsoft Excel. Descriptive statistics were used to simplify, organise, summarise, and plot graphical numerical data (Gray, 2014; Thomas, 2013).

Apps were selected on the basis of accessibility, cost and suitability to fit into a typical OC lesson within a Japanese high school classroom environment. It was decided to use apps, which have a general purpose and could be used in language learning. Siskin (n.d.) refers to these apps as 'repurposed apps' and examples are the timer app and voice memo app which are pre-installed on most smartphones. The Padagogy Wheel was also consulted and is a great tool for sorting out the dozens of apps and stages of Bloom's Digital Taxonomy (Bloom and Kathwohl, 1956; Anderson and Kathwohl, 2001).

The data collection for this study came from six lessons conducted over four days within the classroom at the school. Days two and three consisted of two lessons per day (see Table 3). Each lesson was made up of typical OC topics and stages.

Table 3. Lesson Schedule

\begin{tabular}{|llll|} 
Day & Lesson & Topic & Participants* \\
\hline 1 & 1 & Future Sports & 2 \\
2 & 2 & Theme Parks & 11 \\
2 & 3 & Theme Parks & 3 \\
3 & 4 & Jobs and Careers & 8 \\
3 & 5 & Jobs and Careers & 2 \\
4 & 6 & Music & 13 \\
& & Total & $\mathbf{3 9}$
\end{tabular}

*Note: three students participated in two lessons. There were a total of 36 participants in this study.

Consideration for participants in this research study is of paramount importance and the utmost care was given to their welfare and for their protection (Thomas, 2013), especially as the participants are children aged 14 to 17. Pseudonyms are used throughout this study to protect the identity of the participants (Knock, Rouhshad, Oon and Storch, 2015). As the participants were non-native English speakers all documentation for both the parents and the participants was translated into the students' mother tongue of Japanese and given before the study. Participation was voluntary and all participants had the right to withdraw from the study at any time. 


\section{FINDINGS}

\section{Lesson 1: Future Sports}

To lead-in to the topic and activate schemata the two students browsed Google and selected 'images' to search for future sports. They were then given the chance to share and discuss their findings, which yielded eight counts of interaction $(12.7 \%)$. During the next task, the students watched a YouTube video on future sports and noted down any keywords and phrases in the Evernote app which they then shared (FCI 7.9\%). For the online quiz Kahoot!, the students worked on their own with no interaction recorded $(0.0 \%)$. The penultimate task was a conversation on future sports using the voice recorder and timer apps, which yielded the highest counts of interaction: $44(69.8 \%)$. This was adapted from Nation's 4-3-2 technique (Nation, 1989). In the final task, the students used Evernote and reflected on the lesson, which generated six counts of interaction (6.5\%).
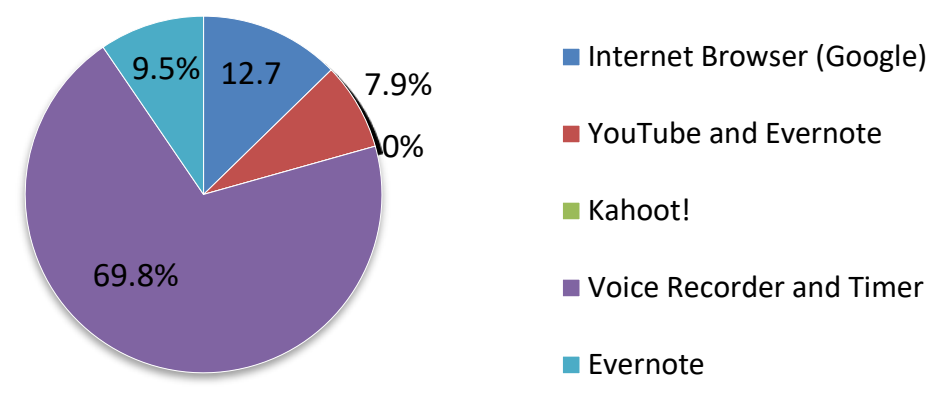

Figure 1. Percentage of Student-student Interaction for Lesson 1

\section{Lesson 2: Theme Parks}

As a warm-up task, the students asked and answered four questions accessed via the QR Scanner app, providing 203 counts of interaction (39.8\%). The students worked well in pairs and showed remarkably high levels of social interaction. The students then watched a YouTube video on theme parks and noted down any keywords and phrases in the smartphone notes app. They shared and discussed their findings which generated a count of 95 (18.6\%). In News Magazine (online) with no interaction recorded $(0.0 \%)$. In the next task, the students were split into groups and played the quiz Kahoot!, which yielded 44 counts of interaction (8.6\%). The students used the 'free chat' feature of the app LINE to have a conversation with their partner and this produced 168 counts of interaction (32.9\%). 


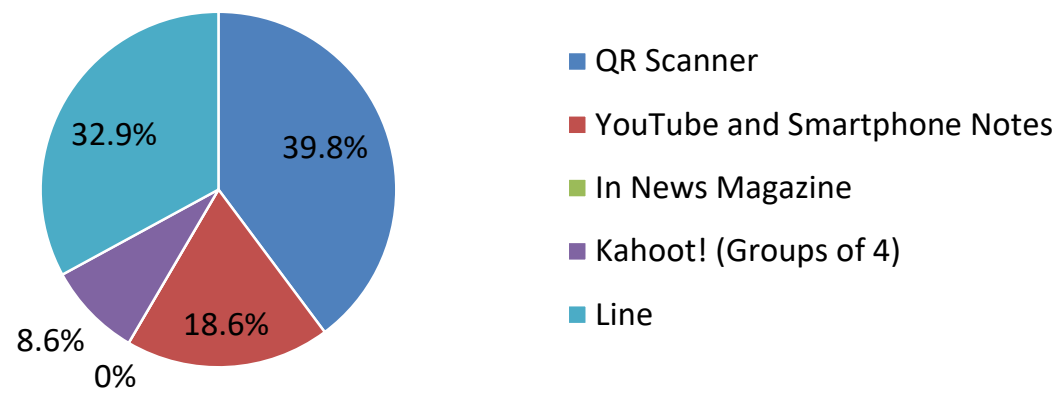

Figure 2. Percentage of Student-student Interaction for Lesson 2

\section{Lesson 3: Theme Parks}

The QR Scanner warmer generated 35 counts of interaction (24.6\%). Negotiation of meaning was very high with Yuzu (the more-advanced other) helping Kaho with vocabulary as she tried to describe it. The following apps yielded FCI: YouTube 13 (9.2\%), In News Magazine 0 (0.0\%), Kahoot! 0 (0.0\%). The final task of the lesson was LINE with a significant FCI of 94 (66.2\%). After the task had ended the teacher brought the students together and had them report and reflect on using LINE. Akira seemed to have an increased sense of confidence. He said, "I get power to speak English fast". He was really pleased with himself and left the lesson on a high (as did the two female participants).

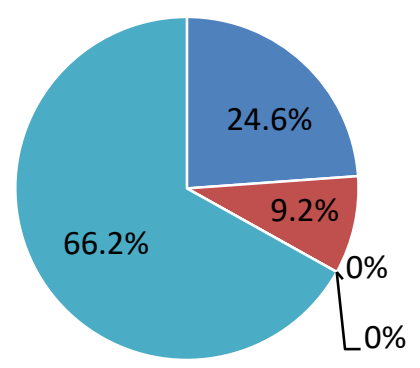

$$
\begin{aligned}
& \text { QR Scanner } \\
& \text { YouTube } \\
& \text { In News Magazine } \\
& \text { Kahoot! } \\
& \text { Line }
\end{aligned}
$$

Figure 3. Percentage of Student-student Interaction for Lesson 3

\section{Lesson 4: Jobs and Careers}

To lead-in to the topic, the students used Google and selected 'images' to search for interesting jobs and this yielded 83 counts of interaction (22.8\%). The students discussed what they had found out. Students then watched a YouTube video on jobs and careers and recorded the audio with their smartphones. This generated an interaction count of $40(11.0 \%)$. During the reading section of In News Magazine, the students used their voice recorders to listen to their reading. They then discussed what they had read, which provided 26 counts of interaction (7.1\%). Kahoot! played individually produced no interaction $(0.0 \%)$. Finally, the students used the 'free chat' feature of the app LINE to have a conversation with their partner and this produced 215 counts of interaction $(59.1 \%)$. 


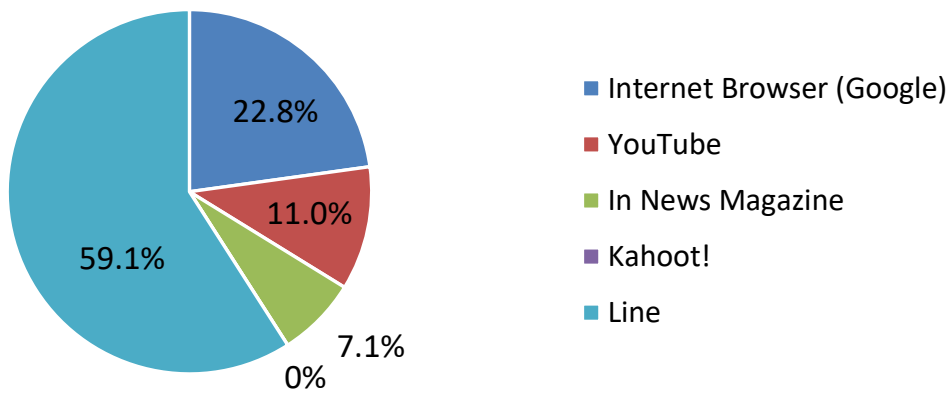

Figure 4. Percentage of Student-student Interaction for Lesson 4

\section{Lesson 5: Jobs and Careers}

During the warm-up task with Google (images) the two students interacted well with a FCI was $23(23.7 \%)$. YouTube $8(8.2 \%)$ and Kahoot! $0(0.0 \%)$ yielded FCI. Reading from In News Magazine produced a FCI of $3(3.1 \%)$. The final task of the lesson was a 'free chat' using LINE. As there were two students and two video cameras, it was possible to separate the students, with one inside and one outside of the classroom. Again using LINE, the students had a high level of interaction, with a frequency count of $63(64.9 \%)$. The students fully enjoyed using LINE - Ken said, "I don't have so many English words. I can image Japanese talking situation but I can't image English". Akihito said, "I use a few vocabulary but this [LINE] is my best".

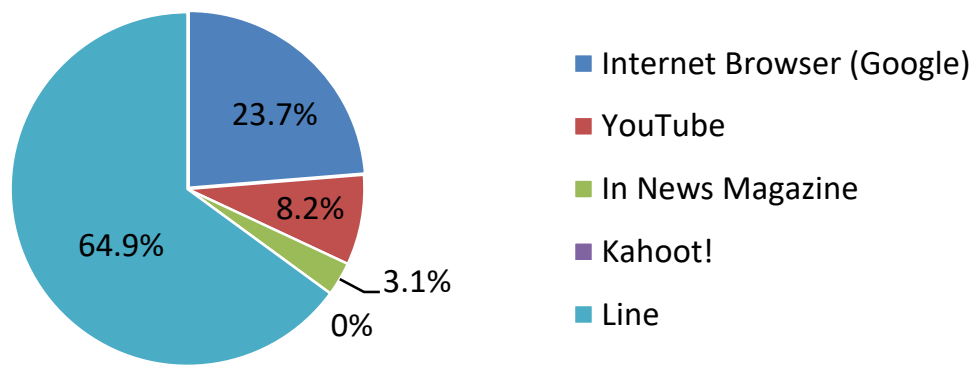

Figure 5. Percentage of Student-student Interaction for Lesson 5

\section{Lesson 6: Music}

The lesson began with a schematic activation warm-up task accessed via the QR Scanner app, which provided 94 counts of interaction (24.9\%). To strengthen vocabulary, the students used Google and selected 'images' to search for the provided vocabulary, which yielded 31 counts of interaction $(8.2 \%)$. Socrative is a web-based quiz and was played in groups by the 13 students and generated 162 counts of interaction (42.9\%). This online quiz was different from Kahoot!, with the students working in teams but using one smartphone as a shared device. The students chose a song from their music library, listened to it with their partner, and 
then had a conversation about it. The music via media player app had a frequency count of $91(24.1 \%)$.

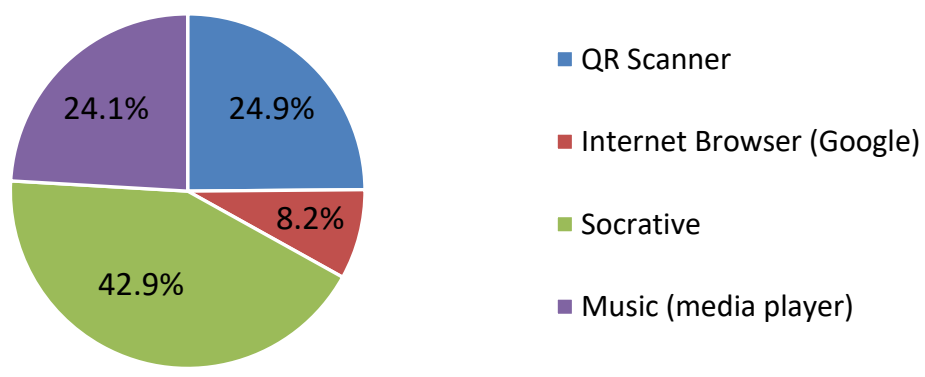

Figure 6. Percentage of Student-student Interaction for Lesson 6

\section{Interaction per Application}

To arrive at an overall measurement, the number of FCI was divided by the number of participants, which gave the value per person, e.g. Google: 15 counts of interaction divided by three students gives five counts per person. It was necessary to apply this calculation, as some of the apps and tasks had been used in one or more lessons. Table 4 shows the total results for all the apps ranked from first (most interaction) to thirteenth (least interaction) position based on FCI and will now be analysed in that order with counts of interaction given per person (PP). Figure 4.7 details each app's count of interaction per person.

Table 4. Total Results of Interaction per Person

\begin{tabular}{|lcccc}
\multicolumn{1}{c}{ Apps/Tasks } & $\begin{array}{c}\text { Frequency } \\
\text { Total }\end{array}$ & $\begin{array}{c}\text { No. of } \\
\text { Students }\end{array}$ & $\begin{array}{c}\text { Frequency per } \\
\text { Person }\end{array}$ & Rank \\
\hline LINE & 540 & 24 & 22.5 & 1 \\
\hline Voice Recorder and Timer & 44 & 2 & 22.0 & 2 \\
\hline Socrative & 162 & 13 & 12.5 & 3 \\
\hline QR Scanner Mingler & 332 & 27 & 12.3 & 4 \\
\hline YouTube and Smartphone Notes & 95 & 11 & 8.6 & 5 \\
\hline Smartphone music (media player) & 91 & 13 & 7.0 & 6 \\
Internet Browser (Google) & 145 & 25 & 5.8 & 7 \\
\hline YouTube & 61 & 13 & 4.7 & 8 \\
\hline Kahoot! In Groups & 44 & 11 & 4.0 & 9 \\
\hline Evernote & 5 & 2 & 2.5 & $=10$ \\
YouTube with Evernote & 5 & 2 & 2.5 & $=10$ \\
\hline In News Magazine & 29 & 24 & 1.2 & 12 \\
\hline Kahoot! & 0 & 15 & 0.0 & 13
\end{tabular}




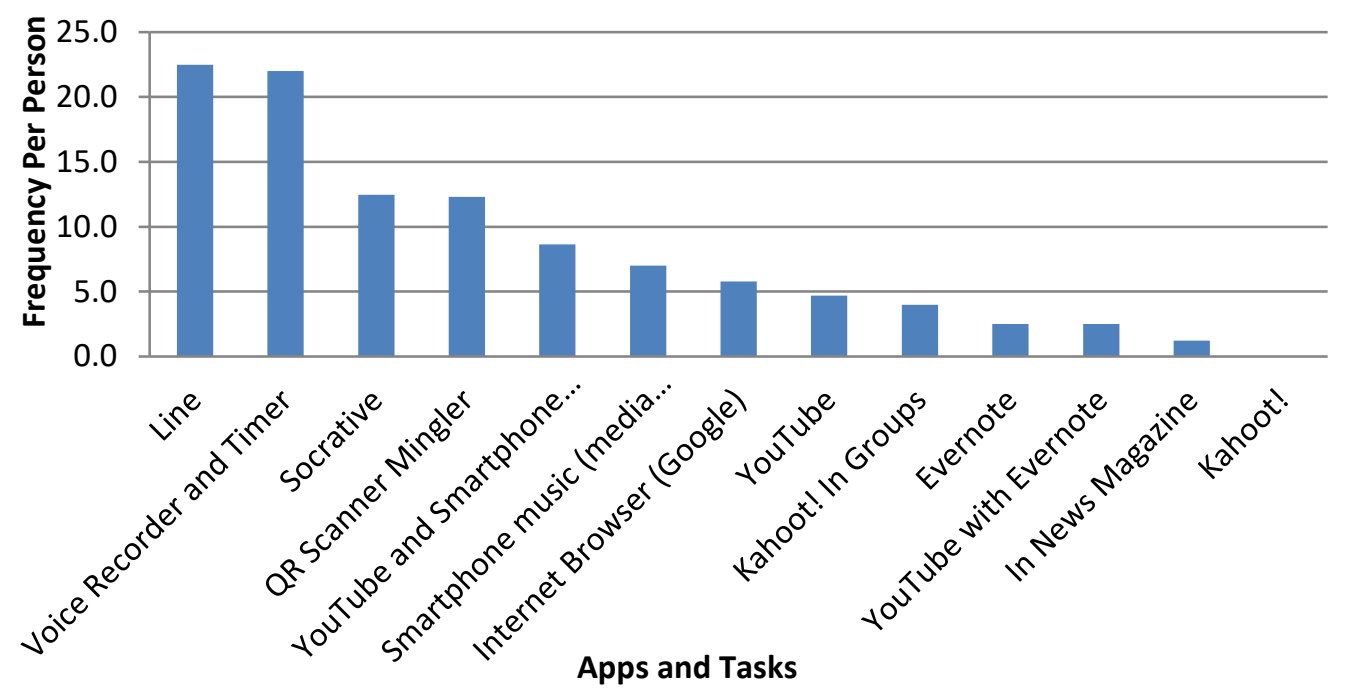

Figure 7. Event Sample of Interaction

The free messaging app LINE, used for the purpose of having a spoken conversation, was the most successful in encouraging student-student interaction (22.5 PP). LINE required collaborative input with the technology used as a medium for meaning-making (Burnett, 2010).

The Voice Recorder and Timer required step-by-step input to achieve the goal of building up better-spoken conversation. Students progressed by listening to their conversation and then repeating the conversation which achieved a FCI of 22 PP.

Socrative achieved a FCI of 12.5 PP. This task was a problem-solving task in which the learners had to collaborate to find a solution (answer) that was acceptable to the group (Mackey, 2012), where the technology acted as a site for interaction (Burnett, 2010).

QR Scanner Mingler turned out to be an easy-to-use app, which allowed the students to access the given media quickly and accurately, e.g. website link. When used as a substitution element of the SAMR Model (Romrell, Kidder, and Wood, 2014) to provide the questions in lessons 2, 3 and 6 the app yielded a FCI of 12.3 and encouraged great collaborative input by the participants.

YouTube and Smartphone Notes required the learners to collaborate together and interact in a step-by-step manner and produced the fifth highest FCI of 8.6 PP.

Smartphone music (media player) made a significant impact as the students' motivation and interaction was high. This required collaborative and step-by-step input by the learners with a FCI of 7 PP.

Internet Browser (Google) had a FCI of 5.8 PP and was used for schematic activation and gave the students a chance to research vocabulary and the topic for themselves. The learners shared their information, with the task and technology used a deliverer of literacy (Burnett, 2010). 
YouTube proved to be a great tool, as it provided students with great stimulation and created a high level of engagement. When YouTube used as a listening activity that required students to discuss what they learned, this yielded more interaction (FCI of $4.7 \mathrm{PP}$ ).

Kahoot!, when played in groups, was similar to Socrative in that it supported a problem-solving task for the learners and yielded a FCI of 4 PP. When played individually Kahoot! gathered no counts of interaction and was the weakest in terms of facilitating interaction.

Evernote, when used as a reflection tool, produced a FCI of 2.5 PP and required collaborative input from the learners. YouTube with Evernote yielded a FCI of also 2.5 PP.

The reading tasks via In News Magazine provided a FCI of 1.2 PP and were used as a lead-in task to the quiz.

\section{DISCUSSION}

The present study investigates how the use of smartphones can support interaction in the classroom, and in particular which smartphone apps and tasks foster better student-student interaction and complete a gap in the previous research.

\section{Discussion on Specific Apps}

The thirteen apps will be discussed and interpreted in the order of FCI from most interaction to least interaction, utilising the obtained results.

LINE was used in four lessons (2, 3, 4 and 5), with the technology being used as a medium for meaning-making (Burnett, 2010) within a sociocultural model of literacy. The students were quick to participate using this mode of collaborative communication. The researcher sensed they almost had to keep the conversation going as it was a phone call - there were no awkward silences during the conversation. It was surprising how well this app worked, given that many students over the 17 years that the researcher has been teaching are consistently concerned about talking on the phone. The findings are broadly consistent with (Pollard, 2015) in that all the students participated very well with the task being very studentcentred, which appeared to motivate the learners. The findings of using the LINE app concur with Pollard (2015) that the task is "relatively simple to set up and appears to provide motivation to the language learner, along with introducing and developing the notion of learner autonomy" (p.31). As there were only two students in lesson 5 they were split up with one inside and one outside of the classroom, which added more authenticity.

The Voice Recorder and Timer were unfortunately only used once (lesson 1) and proved to be highly productive for interaction. The task was adapted from the 4-3-2 technique (Nation, 1989) but instead of speaking about the same topic for four, three and then two minutes, the students recorded their conversation and then gave feedback to improve it the second time around. This is consistent with Pollard's 'Spoken Response' activity (Pollard, 2015) (As per the FCI, the conversation improved the second time around). Focusing on the form which is known as 'noticing' or 'consciousness-raising' (Schmidt 2001; Thornbury 2005; 
Ellis 2008) helped the students become more fluent and natural after they identified and corrected their errors.

Socrative was successful at encouraging interaction, as the learners had to negotiate the answers in teams and allowed the students to collaborate using a shared device. The findings concur with (Chung et al., 2013) that although mobile devices enable learners to interact, collaborative learning can be best achieved through shared devices. Certainly, this task confirms that assessment. Adding weight to shared device collaboration (Mavrou et al., 2010) found that sharing devices is "a trigger for conflict resolution strategies, mutual respect, and acceptance of each other's turn, role and responsibilities" (p.499) as well as enhancing interaction through social constructivism.

The next app became an indispensable tool during this research project. The QR Scanner app allows for many uses and was utilised in five out of the six lessons, mainly for a quick and convenient way to access information such as a website. When used to provide information e.g. questions, the QR scanner substituted a hand-out or textbook. In this study, the technology acted as a site for interaction around a text (Burnett, 2010), which is one of a set of three criteria (see Burnett, 2010 for details) that Chik (2015) suggested in her paper for evaluating claims by app developers.

YouTube and Smartphone Notes produced a fifth-placed FCI but the students generally spent too much time staring at their screens and not enough time speaking. Some of the learners seemed to be preoccupied with what they had written. It was clear from reviewing the video again that when students did not study their displays they spent more time socially interacting. This could be explained by what Chung et al. (2013) highlighted in their study: "fragmented interaction patterns" and "a decreased level of activity awareness" (p.189).

The students were very motivated to share their music via the Smartphone music (media player) app and this seemed to stimulate a lot of the students and increased their engagement. As one student explained his/her favourite song the other student listened. It is beneficial to set up this task with an emphasis on followup questions for the listener and demonstrate this conversation fully. The findings for this task are consistent with Mavrou et al. (2010), who opine about the benefits of computers in increasing motivation and interaction.

Internet Browser (Google) was used in four of the lessons (1, 4, 5 and 6) and was an ideal way to activate schemata as the students could browse images on the related topic(s). Browsing the Web is an important part of cognitive development which involves information finding and information discovery which is critical to learning (Marchionini, 2006). The findings are broadly consistent with Pollard (2015) that images should be "tied to the thematic properties of the syllabus" (p.29). As Pollard (2015) also points out in his 'Picture Prompt' activity, describing images is a part of the speaking section of the Test of English for International Communication (TOEIC) (Educational Testing Service, 2019) and this type of task "seems custom-made for smartphones" (Pollard, 2015, p.29). Also, arguing the benefits of using the Internet for schema activation, Chung et al. (2013) state that although web browsing can be an individual task, reporting back the 
findings can help students collaborate and improve face-to-face interaction. A problem arises when the learners do not report back as happened between several partners - they were engrossed (especially the junior 3 lower-level students) in the images and did not speak as much as was hoped for.

YouTube provided great stimulation to the students; however, the speaking on the videos was very fast so the students could have really made use of the notes/memo app on their smartphone (which they did in lesson 1) to help aid discussion.

Kahoot! played in groups was similar to Socrative discussed above in the fact that it is an online quiz game and had the same collaborative and shared device characteristics. Like Socrative, Kahoot! brings a lot of enthusiasm and fun into the classroom and the students really enjoyed playing it. Kahoot! did not score as high as Socrative in FCI, due to a difference in the duration of how long the students had to answer. Kahoot! had a 30-second countdown which added to the excitement and intensity. However, this did not leave a great deal of time for the students to interact with one-word utterances of interaction common during play.

Evernote and YouTube with Evernote are in equal tenth position for FCI. Evernote is a highly adaptive app designed for note-taking, organizing, and archiving. However, in this study, it was not utilised to its full potential.

In News Magazine was used for the reading extracts which linked directly to the lesson topic and the quiz Kahoot! As the reading linked to Kahoot! the text was read by the teacher and there was not a lot of opportunity for student-student interaction. Kahoot! when played individually gathered no student-student interaction.

\section{General Discussion on Apps and Interaction}

Chung et al. (2013) point to the benefits of a shared workspace alongside mobile computers, with their results suggesting that a shared visual workspace is required to boost information exchange that is favourable for discussion and social interaction. As happened many times during this study the learners focused on their individual displays and this hampered their discussion, and hence interaction in some tasks e.g. Evernote, smartphone Notes, and Google images.

In all six lessons, there was a main display (Interactive whiteboard) that demonstrated the tasks as well as hosting PowerPoint and the Internet. This was extremely useful at expediting instructions quickly and concisely. This visual instructional display dealt with decreasing anxiety and the stress of a lack of operational understanding, which corresponds to the main problems highlighted by Cochrane (2015) in his study. He reported that students felt stressed due to lack of instructions and the teacher-centred approach, and hence they became unmotivated. In contrast to the reported literature, the main display in this study facilitated instructions clearly and reassured students, which instantly motivated the majority of the learners, particularly in larger classes. 
Due to traditional Japanese teaching methods, such as the cognitive processing approach, which stresses repetition (Burrows, 2008; Yoshida, 2008), Japanese students have a fascination with accuracy and are more concerned about focusing on form to the detriment of fluency (Pollard, 2015). Given that the primary mandate of OC is on speaking, low levels of fluency can hinder communication and affect the students' success on the course. The voice memo/recorder app allows students to combine speaking with a focus on form. As noted in Pollard (2015) pair and group work with collaborative learning are useful at constructing greater fluency and accuracy (Bygate, 2005). Pair and group work using the voice memo app provides scaffolding for learners to co-construct meaning, who can then rehearse their conversation. The resulting goal is that fluency levels are improved from the focus on form (Nation, 1989) and strikes a nice balance.

Kim and Kwon (2012) and Chik (2015) both argued in their studies that the apps that they evaluated were not suitable for meaningful interaction. Kim and Kwon (2012) comment that most of the apps "require cognitive language learning style and seldom provide socially interactive learning opportunity" (p.52). While the "ESL apps employed various modes and functions of multimedia" they were not used properly for collaborative and constructive instruction as opposed to what is called for is "more active use of authentic context, socially interactive tasks" (Kim and Kwon, 2012, p.53). Chik (2015) points to the benefits of language learning in the classroom from experts (teachers) rather than learning from apps developed from unrecognised EFL developers and publishers and casts doubt on many app developers' credibility. She posits that although EFL apps are useful in supplementing "wordlist learning at home" it is "urgent to prioritise meaningful interaction in EFL classes" (Chik, 2015, p.41). This gives credence to the decision in this study to accommodate repurposed apps, which were employed in an authentic classroom setting.

Kuo (2011) highlighted the strength of student-student interaction in the pedagogical classroom and acknowledged interaction that takes place in SLA. However, in her findings, she stated that traits of the Interaction Hypothesis (Long, 1996) and Sociocultural Theory (Vygotsky, 1978) present a significant setback to SLA. 'Learners' apparent need for corrective feedback and the more advanced other (but the lack of it) then further diminishes the perceived usefulness of classroom student-student interaction" (Kuo, 2011, p.288). She argues that because interaction takes place, it does not necessarily signify that it is meaningful, and only satisfies a demand for speaking practice, which does not facilitate SLA. The researcher comes back to the male student Akira from lesson 3 who interacted in negotiation of meaning and then went on to speak well using the app LINE. The fact that he interacted in 'noticing' and corrective feedback and then improved in production of conversation demonstrates the effectiveness of interaction in facilitating SLA.

\section{CONCLUSION}

The findings in this small-scale study can contribute to the development of MALL, especially in identifying and improving peer interaction in the classroom. If a teacher's goal is to increase interaction between students, having knowledge of 
which apps could accomplish this task would be valuable and worthwhile. The results showed which apps yielded the highest (LINE) and lowest (Kahoot!) FCI. It was found that tasks which required learners to negotiate meaning and not continuously look at their smartphone displays encouraged greater interaction and facilitated increased communication. These results are broadly consistent with Chung et al. (2013) and Cochrane (2015). The 'repurposed' apps studied in this project are noteworthy in that they can be used in students' real-world lives outside of the classroom such as LINE, Voice Memo, QR Scanner, Timer, YouTube, etc.

This study has some possible limitations, such as the reliability of data collection of structured observation with frequency counts, which could be improved by having additional researchers view the videos (Thomas, 2013). The lessons could be taught using a MALL pedagogy, with a focus on flexible practices with learner-centred learning opportunities for interaction and collaboration (Kim and Kwon, 2012; Chik, 2015). In addition, the apps used in this study were selected by the researcher and were thought to be the best for the current study. Over the course of carrying out this research, alternative apps have come to the researcher's attention which might have added more variety and value to the lessons.

Further studies are required to establish a definitive list of apps that are the most successful in encouraging student-student interaction. Future longitudinal empirical research could be conducted to evaluate and analyse apps and interaction over a term or an entire academic year which would provide more substantial and worthwhile data. Experimental research could be employed (with experimental and control groups) to find out how much (or less) interaction takes place with or without the use of smartphones and apps in the classroom.

\section{REFERENCES}

Anderson, L. W., and Krathwohl, D. R., (Eds.) (2001) A Taxonomy for Learning, Teaching, and Assessing: A Revision of Bloom's Taxonomy of Educational Objectives. Allyn and Bacon. Boston, MA (Pearson Education Group)

Bales, R. F. (1951). Interactional Process Analysis. Cambridge, Addison Wesley.

Beaver, A. (2016). Social interaction and design in an online multiliteracy center (Unpublished doctoral dissertation). University Of Colorado at Boulder.

Bellack, A. A. (1966). The language of the classroom. New York: Teachers College Press, Teachers College, Columbia University.

Bicen, H., and Kocakoyun, S. (2013). The evaluation of the most used mobile devices applications by students. Procedia - Social and Behavioral Sciences, 89, 756-760.

Bloom, B.S. and Krathwohl, D. R. (1956) Taxonomy of Educational Objectives: The Classification of Educational Goals, by a committee of college and university examiners. Handbook I: Cognitive Domain. NY, NY: Longmans, Green 
Brett, P. (2011). Students' experiences and engagement with SMS for learning in higher education. Innovations in Edu. and Teaching Int., 48(2), 137-147.

Brown, J. D. (2014). Mixed methods research for TESOL. Edinburgh: Edinburgh University Press.

Burnett, C. (2010). Technology and literacy in early childhood educational settings: A review of research. Journal of Early Childhood Literacy, 10(3), 247-270.

Burrows, C. (2008). Socio-cultural barriers facing TBL in Japan. The Language Teacher, (32)8, 15-19.

Burston, J. (2014). The reality of MALL project implementations: Still on the fringes. CALICO Journal, 31(1), 43-65.

Bygate, M. 2005. Structuring learning within the flux of communication: A role for constructive repetition in oral language pedagogy. In New dimensions in the teaching of oral communication, ed. J. A. Foley, 70-90. Singapore: SEAMEO Regional Language Centre.

Caballe, S., Xhada, F., Baroli, L. (2010). Using mobile devices to support online collaborative learning. Mobile Information Systems, 6, 27-47.

Caldwell, K., and Atwal, A. (2005). Non-participant observation: Using video tapes to collect data in nursing research. Nurse Researcher, 13(2), 42-54.

Chang, S.E., and Vera Pa, Y.H. (2011). Exploring factors influencing mobile users' intention to adopt multimedia messaging service. Behav. Inf. Technol, 30(5), 659-672.

Chik, A. (2015). English Language Teaching Apps: Reconceptualizing Learners, Parents, and Teachers. In: Dixon, E, and Thomas, M. (Eds) Researching Language Learner Interactions Online: From Social Media to MOOCs. CALICO Monograph Series (13), 29 - 44.

Chung, C. W., Lee, C. C., and Liu, C. C. (2013). Investigating face-to-face peer interaction patterns in a collaborative Web discovery task: The benefits of a shared display. Journal of Computer Assisted Learning, 29(2), 188-206.

Cochrane, R. (2015). Activities and reflection for influencing beliefs about learning with smartphones. Critical CALL - Proceedings of the 2015 EUROCALL Conference, Padova, Italy, 138-143.

Copland, F., and Garton, S. (2014). Editor's choice: Key themes and future directions in teaching English to young learners: Introduction to the Special

Issue. ELT Journal, 68(3), 223-230.

Croll, P. (1986). Systematic classroom observation. London: Falmer Press. 
Dashtestani, R. (2015). Moving bravely towards mobile learning: Iranian students' use of mobile devices for learning English as a foreign language. Computer Assisted Language Learning, 1-18.

Donato, R. (1994). Collective scaffolding in second language learning. In J. Lantolf and G. Appel (Eds.), Vygotskian approaches to second language research 33-56. Norwood, NJ: Ablex.

Educational Testing Service. 2014. Test content. TOEIC. Retrieved August 2019 from www.ets.org/toeic/speaking_writing/about/content.

Ellis, R. (2008). The study of second language acquisition. Oxford: Oxford University Press.

Flanders, N. A. (1970) PEPBL: Methodology working paper 6: Flanders Interactional Analysis. Retrieved August, 2016 from the World Wide Web: www.hebes.mds.ac.uk

Frymier, A. B. (2005). Students' classroom communication effectiveness. Communication Quarterly, 53, 197-212.

Fujimoto, C. (2012). Perceptions of mobile language learning in Australia: How ready are learners to study on the move? JALT CALL Journal, 8(3), 165195

Fukuzawa, R. and LeTendre, G. (2001). Intense Years: How Japanese Adolescents Balance School, Family and Friends. New York: Routledge.

Giles, H., Mulac, A., Bradac, J. J., and Johnson, P. (1987). Speech accommodation theory: The first decade and beyond. In M. McLaughlin (Ed.), Communication Yearbook, 10, 13-48. New York, NY: Routledge.

Gray, D. (2014). Doing research in the real world (3rd ed.). London: Sage Publications.

Gutiérrez, G. A. (2006). Sociocultural theory and its application to CALL: A study of the computer and its relevance as a mediational tool in the process of collaborative activity. ReCALL, 18(02), 230-250.

Holec, H. (1981). Autonomy in foreign language learning. Oxford: Pergamon.

Kim, H., and Kwon, Y. (2012). Exploring smartphone applications for effective

mobile-assisted language learning. Multimedia-Assisted Language Learning, 15(1), 31-57.

Knoch, U., Rouhshad, A., Oon, S. P., and Storch, N. (2015). What happens to ESL students' writing after three years of study at an English medium university? Journal of Second Language Writing, 28, 39-52. 
Mobile phone users in Japan 2013-2020 | Statistics. (2016, June 10). Retrieved August 30, 2019, from https://www.statista.com/statistics/274672/forecastof-mobile-phone-users-in-japan/

Kukulska-Hulme, A. (2009). Will mobile learning change language learning? ReCall, 21(2), 157-165.

Kukulska-Hulme, A. and Shield, L. (2008). An overview of mobile assisted language learning: From content delivery to supported collaboration and interaction. ReCALL, 20, 271-289.

Kuo, I. C. V. (2011). Student perceptions of student interaction in a British EFL setting. ELT Journal, 65(3), 281-290.

Lantolf, J. and Thorne, S. L. (2007). Sociocultural Theory and Second Language Learning. In. B. van Patten and J. Williams (eds.), Theories in Second Language Acquisition. 201-224. Mahwah, NJ: Lawrence Erlbaum.

Lockley, T., and Promnitz-Hayashi, L. (2012). Japanese university students' CALL attitudes, aspirations and motivations. CALL-EJ Online, 13(1), 1-16.

Long, M. (1983). 'Native speaker/non-native speaker conversation in the second language classroom', in M. Clarke and J. Handscombe (Eds), On TESOL 82: Pacific perspectives on language and teaching. Washington, DC: TESOL.

Long, M. (1996). 'The role of the linguistic environment in second language acquisition', in W. Ritchie and T. Bhatia (Eds). Handbook of second language acquisition. San Diego: Academic Press, 413-468.

Marchionini, G. (2006). Exploratory search: From finding to understanding. Communications of the ACM, 49, 41-46.

Mavrou, K., Lewis, A., and Douglas, G. (2010). Researching computer-based collaborative learning in inclusive classrooms in Cyprus: The role of the computer in pupils' interaction. British Journal of Educational Technology, 41(3), 486-501.

Mitchell, R., Myles, F., and Marsden, E. (2013). Second language learning theories. New York: Routledge.

Nation, P. (1989). Improving speaking fluency. System, 17, 377-384.

Parcha, J. M. (2014). Accommodating Twitter: Communication Accommodation Theory and Classroom Interactions. Communication Teacher, 28(4), 229235.

Philp, J., Adams, R. J., and Iwashita, N. (2014). Peer interaction and second language learning. Oxon: Routledge.

Pollard, A. (2015). Increasing Awareness and Talk Time through Free Messaging Apps. English Teaching Forum, 25-32. 
Poulou, M. S. (2009). Classroom interactions: Teachers' and students' perceptions. Research in Education, 82, 103-106.

Richards, K. (2003). Qualitative inquiry in TESOL. Basingstoke, England: Palgrave Macmillan.

Robson, C. (2012). Real world research. Chichester, West Sussex: Wiley.

Robson, C., and McCartan, K. (2016). Real world research. Chichester, West Sussex: Wiley.

Saville-Troike, M. (2006). Introducing second language acquisition. Cambridge Introductions to Language and Linguistics.

Schmidt, R. (2001). Attention. In P. Robinson (Ed.), Cognition and second language instruction, 3-32. New York: Cambridge University Press.

Siskin, C. (n.d.). Language Learning Applications for Smartphones, or Small Can Be Beautiful. Retrieved August 30, 2016, from http://www.edvista.com/claire/pres/smartphones/

Stuart, S., Brown, M. I., and Draper, S. W. (2004). Using an electronic voting system in logic lectures : one practitioner's application, (1), 95-102.

Swain, M. (1997) Collaborative dialogue: Its contribution to second language learning. Revista Canaria de Estudios Ingleses, 34, 115-132.

Swain, M. and Lapkin, S. (2001) Focus on form through collaborative dialogue: Exploring task effects. In: Bygate, M., Skehan, P., and Swain, M. (eds.) Researching Pedagogic Tasks: Second Language Learning, Teaching and Testing. London: Longman, 99-18.

Takahashi, T. (2008). Japanese young people, media and everyday life, towards the

internationalizing of media studies. In K. Drotner and S. Livingstone (Eds.), International Handbook of children, media and culture, 413-430. London: Sage.

Thomas, G. (2013). How to do your research project: A guide for students in education and applied social sciences (2nd ed.). Thousand Oaks, CA: SAGE Publications.

Thornbury, S. 2005. Uncovering grammar: How to help grammar emerge. Oxford: Macmillan Education.

Ting, Y. (2013). Using mobile technologies to create interwoven learning interactions: An intuitive design and its evaluation. Computers and Education, 60(1), 1-13.

Troussas, C., Virvou, M., and Alepis, E. (2014). Collaborative Learning: Group Interaction in an Intelligent Mobile-Assisted Multiple Language Learning System. Informatics in Education InfEdu, 13(2), 279-292. 
38 | J. Somerville

Vygotsky, L.S. (1978) Mind in society: the development of higher psychological processes. Cambridge, MA: Harvard University Press.

Yoshida, R. (2008). Learners' perception of corrective feedback in pair work. Foreign Language Annals, 41(3), 525-541.

Zurita, G., and Nussbaum, M. (2004). A constructivist mobile learning environment supported by a wireless handheld network. Journal of Computer Assisted Learning, 20, 235-243. 